\title{
Effect of dietary lipid saturation on the production performance of layers
}

\author{
E.J. King ${ }^{3}$, F.H. de Witt ${ }^{1 \#}$, A. Hugo ${ }^{2}$, H.J. van der Merwe ${ }^{1}$ \& M.D. Fair ${ }^{1}$ \\ ${ }^{1}$ Department of Animal, Wildlife and Grassland Science; ${ }^{2}$ Department of Microbial, Biochemical and Food \\ Biotechnology, PO Box 399, University of the Free State, Bloemfontein 9300 \\ ${ }^{3}$ Nutri Feeds, PO Box 52, Viljoenskroon 9520
}

Copyright resides with the authors in terms of the Creative Commons Attribution 2.5 South African Licence.

See: http://creativecommons.org/licenses/by/2.5/za/

Condition of use: The user may copy, distribute, transmit and adapt the work, but must recognise the authors and the South African Journal of Animal Science

\begin{abstract}
This study investigated the effects of dietary lipid saturation on production parameters of laying hens during the peak-of-lay period. Five isoenergetic (12.6 MJ AME/kg DM) and isonitrogenous (170 g CP/kg DM) diets were formulated, using a control diet (50 : 50 blend of fish- and linseed oil), fish oil (polyunsaturated n-3), sunflower oil (poly-unsaturated n-6), high oleic acid sunflower oil (mono-unsaturated n-9 ) and tallow (saturated) at a $30 \mathrm{~g} / \mathrm{kg}$ inclusion level. Two hundred individually caged HyLine Silver-Brown hens ( 20 weeks of age) were randomly allocated to the five dietary treatments ( $\mathrm{n}=40$ replicates/treatment). Hens received their respective experimental diets until 40 weeks of age. During weeks 24, 28, 32, 36 and 40 all eggs produced, were recorded, individually weighed and the daily feed intake of birds determined. Data for the respective collection weeks were pooled for calculation of production parameters during peak-of-lay. Dietary lipid saturation level had no effect on daily feed intake of hens, hen-day egg production, egg output and live weight of hens during the peak-of-lay period. The mono-unsaturated n-9 diet (high oleic acid sunflower oil) had the lowest feed efficiency (0.47), while that of the control-, polyunsaturated n- 6 (sunflower oil) and the saturated (tallow) treatments were the highest (0.49). Results of the current study suggest that although dietary lipid saturation level had no effect on most of the production performances, it might influence the efficiency of feed utilization.
\end{abstract}

Keywords: Cracked eggs, egg output, feed efficiency, $\alpha$-linolenic-, linoleic-, oleic-, docosahexanoic acid

\#Corresponding author: dewittfh@ufs.ac.za

\section{Introduction}

Supplementary fats and oils are often used in poultry diets due to their numerous nutritional advantages when compared with pure grain-type carbohydrate diets. The energy value of fats and oils are 2.25 times higher than that of the same quantity carbohydrates (McDonald et al., 2002). This will result in a lower heat increment during the digestion and metabolism process with a consequent increased dietary energy density which could compensate for the detrimental effects of high environmental temperatures on feed intake (Leeson \& Summers, 2001). However, to ensure that the beneficial effects of dietary supplementation of fats and oils are maintained, it is crucial to ensure that all nutrients are balanced according to the increased energy density to prevent other nutrient deficiencies (McDonald et al., 2002).

Fats and oils in layer diets also improve palatability, decrease dustiness of the diet, and are a source of essential fatty acids and carry fat-soluble vitamins and their precursors within the body (Leeson \& Summers, 2001). Vegetable and marine oils are normally preferred over fats due to their unsaturated fatty acid content (Palmquist, 2002).

The metabolisable energy value of fat and oil sources used in poultry diets vary according to their specific fatty acid profile, the absorbability from the intestine, free fatty acid contamination and the type and age of birds being fed. Saturated and unsaturated fatty acids work synergistically when they are fed as a dietary blend, resulting in a higher energy value for the blend than when either type of fatty acid would be 
fed individually (Leeson \& Summers, 2001). Ketels \& De Groote (1989) indicated that this synergistic association between types of fatty acids are mainly due to the superior emulsifying capacity of unsaturated fatty acids. However, much controversy still exists regarding the effects of dietary fatty acid saturation on production performances of layers in terms of feed intake, -production, -weight and egg output. These differences in literature could mainly be ascribed to genotype of birds (Bean \& Leeson, 2003), age and phase of production (Grobas et al., 1999), as well as lipid sources and inclusion levels (Novak \& Scheideler, 2001; Yannakopoulos et al., 2005). Controversy in documented literature and the absence of local information necessitated this study in an attempt to provide South African feed producers with some data regarding the effects of dietary lipid saturation levels on egg production performances of laying hens.

The aim of the study was to investigate the effects of dietary lipid saturation on production performance of laying hens during the peak-of-lay period.

\section{Materials and Methods}

Two hundred HyLine Silver-Brown hens (20 weeks of age) were randomly assigned to five dietary treatments, each consisting of 40 replicates per treatment. Five isoenergetic (12.6 MJ AME/kg DM) and isonitrogenous (170 g CP/ $/ \mathrm{kg} \mathrm{DM})$ experimental diets were formulated, using a control diet consisting of a blend (50 : 50) of fish- and linseed oil, deodorised fish oil (poly-unsaturated n-3), sunflower oil (polyunsaturated n-6), high oleic acid (HO) sunflower oil (mono-unsaturated n-9 ) and tallow (saturated) at a 30 $\mathrm{g} / \mathrm{kg}$ inclusion level. The dietary calcium (39.4 g Ca/kg DM) and available phosphorus (3.2 g AvP/kg DM) content as well as the ratio of $\mathrm{Ca}: \mathrm{AvP}(12.3: 1)$ were constant across all treatments. Fatty acid methyl esters (FAME) of the experimental diets were determined by extracting the dietary fat content according to the procedures of Folch et al. (1957). Fatty acid methyl esters were quantified using a Varian GX 3400 flame ionization GC and were expressed as the relative percentage of individual fatty acids (\% FAME) in the sample (Diaz et al., 2005). Birds were housed individually in metabolism cages $\left(1600 \mathrm{~cm}^{2} / \mathrm{bird}\right)$, while feed and water were provided ad libitum. Daily egg production was recorded for individual hens and summarized as hen-day egg production (\%) per week. Shell-less, soft shell and cracked eggs summarized as deformities, were subtracted from the hen-day egg production to calculate the percentage (\%) sellable eggs per week. At 24, 28, 32, 36 and 40 weeks of age, all eggs produced were individually weighed for the calculation of egg output (g). Feed intake was determined individually on a weekly basis and is expressed as average daily feed intake (g/bird/day). Feed efficiency (g/g) was determined as the total egg output (g) divided by the total feed consumed $(\mathrm{g} / \mathrm{g})$. Hens were weighed once a week during the respective collection weeks. Data of the collection weeks were pooled for statistical analysis to determine parameter means for the peak-of-lay period. The effect of dietary lipid saturation on production performances was analyzed using a fully randomized one-way ANOVA design. The PROC ANOVA procedures of the SAS program (SAS, 2001) were used to test for significant $(P<0.05)$ differences between treatments, while Tukey's studentized range (HSD) test was used to separate treatment means.

\section{Results and Discussions}

Dietary lipid saturation had no effect $(P>0.05)$ on parameters such as feed intake, egg production, egg output and live weight of the hens during the peak-of-lay period (Table 1). However, the highly saturated treatment (tallow) resulted in the lowest $(P<0.015)$ percentage sellable eggs $(89 \%)$. This was a direct result of the higher percentage $(10.3 \%)$ of cracked eggs produced by hens in the saturated treatment compared to that of the other treatments (ranging from $1.86 \%$ to $3.86 \%$ of cracked eggs). Additionally, the monounsaturated n-9 diet (high oleic acid sunflower oil), resulted in the lowest $(P<0.001)$ feed efficiency $(0.47)$, while that of the control, poly-unsaturated n-6 (sunflower oil) and saturated (tallow) treatments were the highest (0.49).

Supporting the present study, Grobas et al. (1999) and Yannakopoulos et al. (2005) also reported that dietary lipid saturation had no effect $(P>0.05)$ on the daily feed intake and live weight of laying hens. Additionally, Cachaldora et al. (2008) reported only a tendency $(P=0.06)$ that lard (palmitic acid $=22.8 \%$; oleic acid $=42.8 \%$ ) resulted in a higher body weight gain (220 g vs. $136 \mathrm{~g})$ in hens compared to linseed oil (oleic acid $=19.2 \% ; \alpha$-linolenic $=47.7 \%$ ). The increase in cracked eggshells observed in the saturated fatty acid treatment could possibly be linked to either (i) the eggshell ultra structure in terms of calcium salt deposition on the external shell membrane as reported by Roberts (2004) or (ii) the formation of Ca-soaps due to free fatty acids from saturated fat sources that are not absorbed (Atteh \& Leeson, 1985). The poor feed 
efficiency (FE) of the mono-unsaturated n-9 treatment could only be explained partly by the collective effects of respectively the highest feed intake $(108.9 \mathrm{~g} / \mathrm{b} / \mathrm{d})$ and the lowest egg output $(357.5 \mathrm{~g} / \mathrm{b})$, although these results were not statistically significant $(P>0.05)$. Considering the effects of dietary lipid saturation on the percentage sellable eggs (Figure 1) and feed efficiency of hens (Figure 2) between treatment parameter means and collection weeks, it is evident that some variation $(P<0.001)$ occurs between collection weeks within a specific dietary treatment. It is, however, evident that irrespective of collection week, the saturated treatment (Tallow inclusion) resulted in the lowest percentage of sellable eggs.

Table 1 Mean \pm SD effects of dietary lipid saturation on layer performance during the peak-of-lay period $(\leq 40$ weeks of age $)$

\begin{tabular}{|c|c|c|c|c|c|c|c|}
\hline Parameters & Control & $\begin{array}{c}\text { PUFA } \\
(n-3)\end{array}$ & $\begin{array}{c}\text { PUFA } \\
(n-6)\end{array}$ & $\begin{array}{c}\text { MUFA } \\
(n-9)\end{array}$ & SATS & $\begin{array}{c}\text { Significance } \\
(P)\end{array}$ & $\begin{array}{l}\mathrm{CV} \\
(\%) \\
\end{array}$ \\
\hline Daily feed intake (g/bird/day) & $\begin{array}{c}106.4 \pm \\
6.4\end{array}$ & $\begin{array}{c}107.4 \pm \\
8.1\end{array}$ & $\begin{array}{c}108.3 \pm \\
7.9\end{array}$ & $\begin{array}{c}108.9 \pm \\
7.1\end{array}$ & $\begin{array}{c}106.0 \pm \\
6.9\end{array}$ & 0.36 & 6.82 \\
\hline Hen-day egg production (\%) & $\begin{array}{c}95.4 \pm \\
3.9\end{array}$ & $\begin{array}{c}94.1 \pm \\
5.9\end{array}$ & $\begin{array}{c}95.9 \pm \\
4.84\end{array}$ & $\begin{array}{c}94.6 \pm \\
5.4\end{array}$ & $\begin{array}{c}96.1 \pm \\
4.8\end{array}$ & 0.32 & 5.28 \\
\hline Sellable eggs (\%) & $\begin{array}{c}95.8^{\mathrm{ab}} \pm \\
7.37\end{array}$ & $\begin{array}{c}97.9^{\mathrm{a}} \pm \\
3.8\end{array}$ & $\begin{array}{c}96.5^{\mathrm{ab}} \pm \\
12.0\end{array}$ & $\begin{array}{c}97.1^{\mathrm{a}} \pm \\
8.4\end{array}$ & $\begin{array}{c}89.2^{\mathrm{b}} \pm \\
22.2\end{array}$ & $<0.015$ & 13.03 \\
\hline Egg output (g) & $\begin{array}{c}366.6 \pm \\
19.8\end{array}$ & $\begin{array}{c}358.1 \pm \\
23.2\end{array}$ & $\begin{array}{c}368.5 \pm \\
23.8\end{array}$ & $\begin{array}{c}357.5 \pm \\
23.4\end{array}$ & $\begin{array}{c}364.4 \pm \\
28.1\end{array}$ & 0.14 & 5.56 \\
\hline Feed efficiency (g/g) & $\begin{array}{c}0.49^{\mathrm{a}} \pm \\
0.03\end{array}$ & $\begin{array}{c}0.48^{\mathrm{ab}} \pm \\
0.03\end{array}$ & $\begin{array}{c}0.49^{\mathrm{ab}} \pm \\
0.02\end{array}$ & $\begin{array}{c}0.47^{\mathrm{b}} \pm \\
0.02\end{array}$ & $\begin{array}{c}0.49^{\mathrm{a}} \pm \\
0.03\end{array}$ & $<0.001$ & 5.52 \\
\hline Live weight (g) & $\begin{array}{c}1706 \pm \\
105\end{array}$ & $\begin{array}{c}1691 \pm \\
119\end{array}$ & $\begin{array}{c}1731 \pm \\
110\end{array}$ & $1711 \pm 99$ & $\begin{array}{c}1729 \pm \\
108\end{array}$ & 0.43 & 6.36 \\
\hline
\end{tabular}

${ }^{\mathrm{a}, \mathrm{b}}$ Means within row with different superscripts differ significantly at $P<0.05$.

PUFA: poly-unsaturated fatty acid; MUFA: mono-unsaturated fatty acid; SATS: saturated fatty acid.

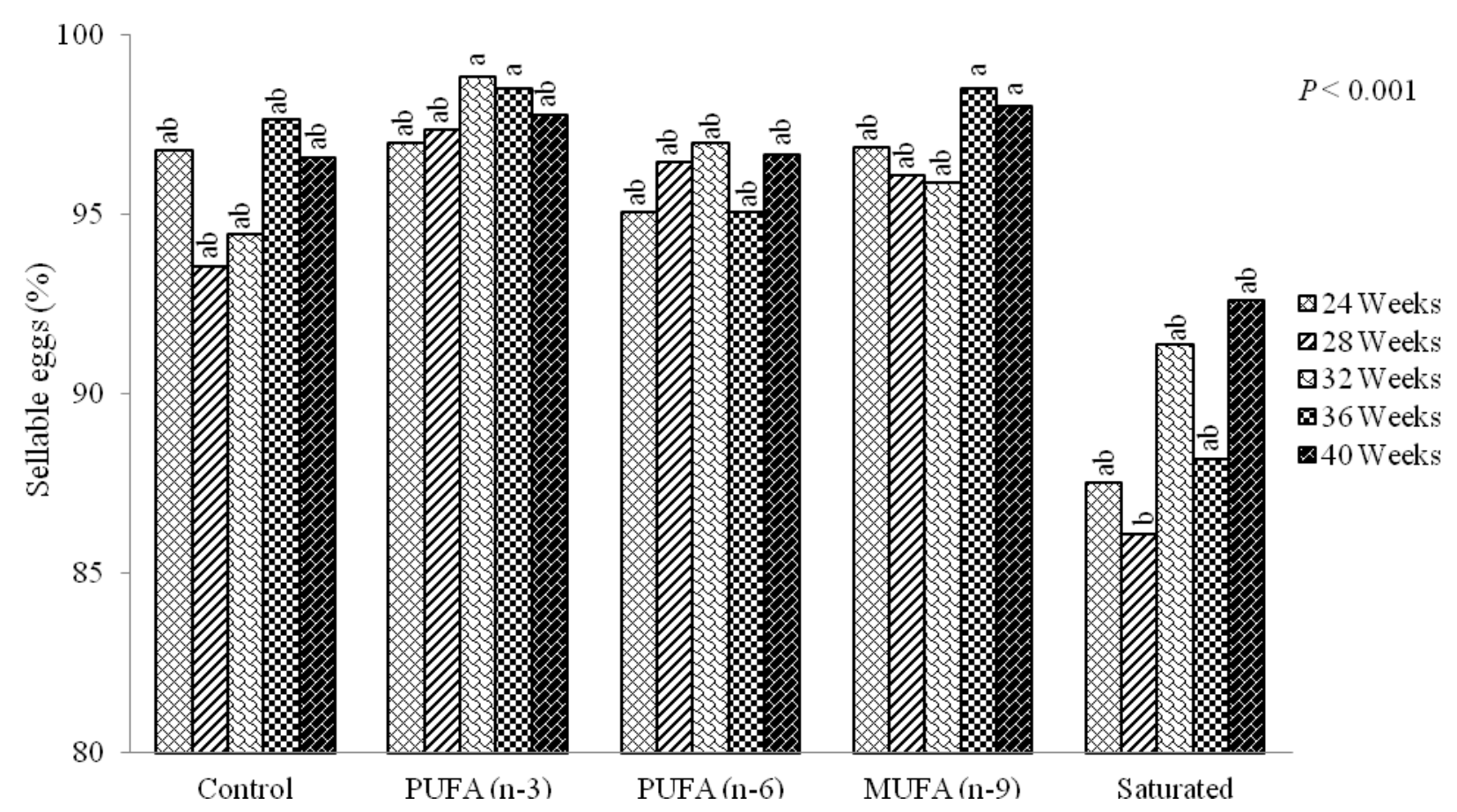

Figure 1 Effect of dietary lipid saturation and collection week on percentage sellable eggs.

(PUFA: poly-unsaturated fatty acid; MUFA: mono-unsaturated fatty acid; SATS: saturated fatty acid). 


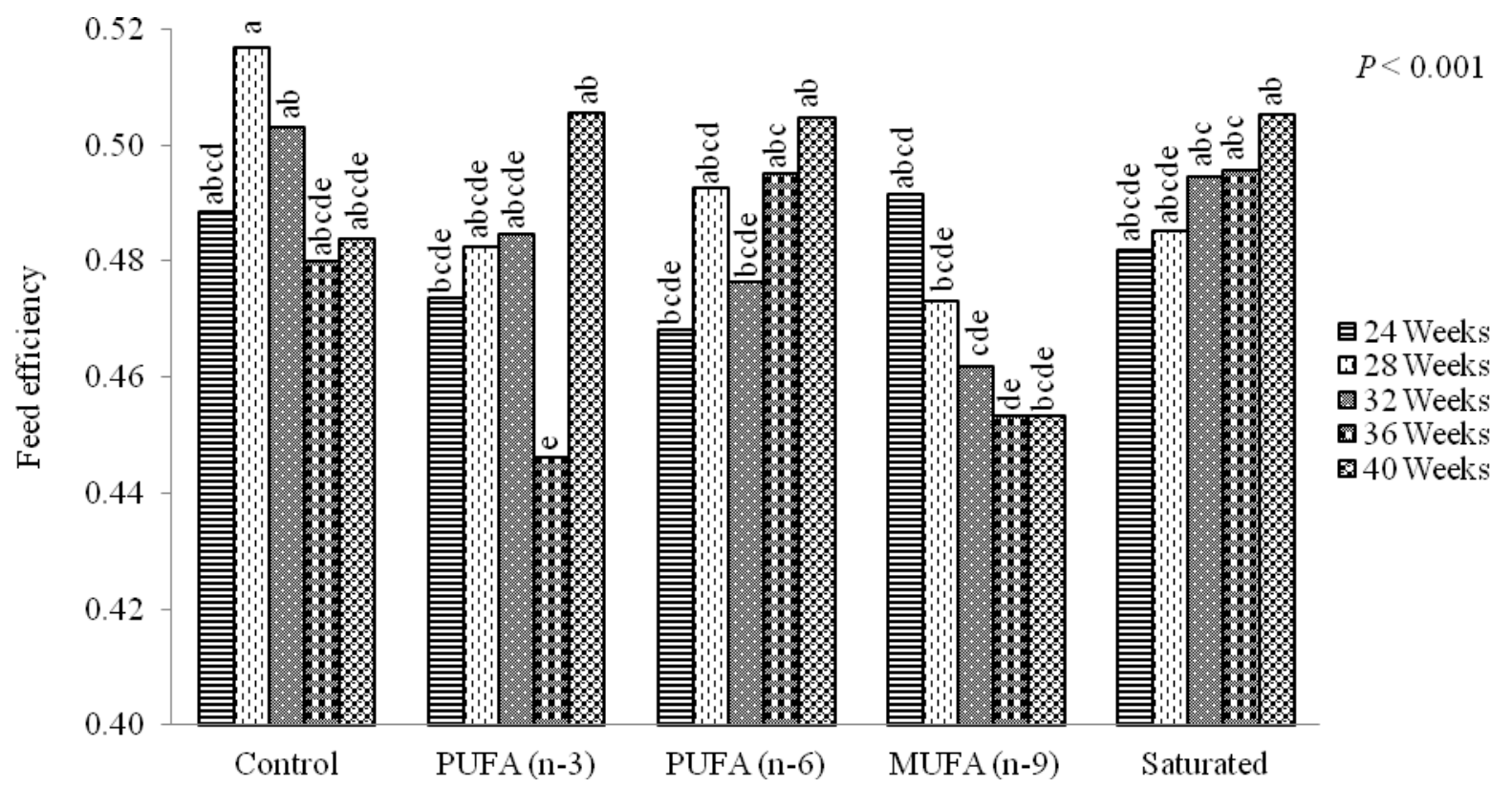

Figure 2 Effect of dietary lipid saturation and collection week on feed efficiency.

(PUFA: poly-unsaturated fatty acid; MUFA: mono-unsaturated fatty acid; SATS: saturated fatty acid).

\section{Conclusions}

Dietary lipid saturation had no effect on most of the production performances evaluated during the peak-of-lay period. However, an increase in dietary saturation (tallow treatment) reduced the number of sellable eggs produced, mainly due to a decrease in intact eggshells, while the diet high in mono-unsaturated n-9 fatty acids (high oleic acid sunflower oil treatment) resulted in the lowest feed efficiency. Results of the present study suggest that although the effects of dietary lipid saturation provoked a limited response in certain production parameters, it definitely needs consideration during diet formulation for laying hens to prevent a depressing effect on economical and feed efficiency parameters.

\section{Acknowledgements}

The authors wish to acknowledge Nutri Feeds, Energy oil and Vergezocht HO oils for their technical and financial support during the trial.

\section{References}

Atteh, J.O. \& Leeson, S., 1984. Effects of dietary saturated or unsaturated fatty acids and calcium levels on performance and mineral metabolism of broiler chicks. Poult. Sci. 63, 2252-2260.

Bean, L.D. \& Leeson, S., 2003. Long-term effects of feeding flaxseed on performance and egg fatty acid composition of brown and white hens. Poult. Sci. 82, 388-394.

Cachaldora, P., Garcia-Rebollar, P., Alvarez, C., De Blas, J.C. \& Mendez, J., 2008. Effect of the type and the level of fish oil supplementation on yolk fat composition and n-3 fatty acid deposition efficiency in laying hens. Anim. Feed Sci. Technol. 141, 104-114.

Diaz, M.T., Alvarez, I., De La Fuente, J., Sanudo, C., Campo, M.M., Oliver, M.A., Font i Furnols, M., Montossi, F., San Julian, R., Nute, G.R. \& Caneque, V., 2005. Fatty acid composition of meat from typical lamb production systems of Spain, United Kingdom, Germany and Uruguay. Meat Sci. 71, 256-263.

Folch, J., Lees, M. \& Sloane-Stanley, G.H., 1957. A simple method for the isolation and purification of total lipids from animal tissue. J. Biol. Chem. 226, 497-509.

Grobas, S., Mendez, J., De Blas, C. \& Mateos, G.G., 1999. Laying hen productivity as affected by energy, supplemental fat, and linoleic acid concentration of the diet. Poult. Sci. 78, 1542-1551. 
Ketels, E. \& De Groote, G., 1989. Effect of ratio of unsaturated to saturated fatty acids of the dietary lipid fraction on the utilisation and metabolisable energy of added fats in young chicks. Poult. Sci. 68, 1506-1512.

Leeson, S. \& Summers, J.D., 2001. Nutrition of the chicken. $4^{\text {th }}$ Edition. University books, Guelph, Canada. pp. 35-99.

McDonald, P., Edwards, R.A., Greenhalgh, J.F.D, \& Morgan, C.A., 2002. Animal Nutrition, $6^{\text {th }}$ Edition. Pearston Education Limited, Edinburgh Gate, Harlow, Essex, U.K. pp. 199-244.

Novak, C. \& Scheideler, S.E., 2001. Long-term effects of feeding flaxseed-based diets.1. Egg production parameters, components, and eggshell quality in two strains of laying hens. Poult. Sci. 80, 1480-1489.

Palmquist, D.L., 2002. An appraisal of fats and fatty acids. In: Poultry feedstuffs; supply, composition and nutritive values. Eds. McNab, J.M. \& Boorman, K.N. CABI publishing, Wallington, Oxon, U.K. pp. 87-98.

Roberts, J.L., 2004. Factors affecting egg internal quality and egg shell quality in laying hens. J. Poult. Sci. 41, 161-177.

SAS, 2001. SAS ${ }^{\circledR}$ User’s Guide. Version 6.12. SAS Institute Inc. Cary, N.C., USA.

Yannakopoulos, A., Tserveni-Gousi, A. \& Christaki, E., 2005. Enhanced egg production in practice: The case of bio-omega-3 eggs. Int. J. Poult. Sci. 4, 531-535. 